Article

\title{
Stress in Caregivers and Children with a Developmental Disorder Who Receive Rehabilitation
}

\author{
Sung Hyun Kim ${ }^{1}$, In Young Sung ${ }^{2, *}$, Eun Jae Ko ${ }^{2}$, Jieun Park ${ }^{2}$ and Nayoung Heo ${ }^{2}$ \\ 1 Department of Rehabilitation Medicine, University of Ulsan College of Medicine, Ulsan 44033, Korea; \\ 0735159@uuh.ulsan.kr \\ 2 Department of Rehabilitation Medicine, Asan Medical Center, University of Ulsan College of Medicine, \\ Seoul 05505, Korea; gonjae0610@gmail.com (E.J.K.); pje3117@naver.com (J.P.); \\ nayoung.heo@amc.seoul.kr (N.H.) \\ * Correspondence: iysung56@gmail.com; Tel.: +82-2-3010-3410; Fax: +82-2-485-8381
}

Received: 14 July 2020; Accepted: 11 September 2020; Published: 15 September 2020

\begin{abstract}
This study aimed to evaluate the stress levels of caregivers and children with developmental disorders who were receiving rehabilitation treatment. The relationships between stress levels and factors such as early rehabilitation and home rehabilitation were quantified. Methods: This study was conducted in children with development disorders, aged from 1.5 years to 18 years, who were undergoing rehabilitation. The Korean version of the Child Behavior Checklist (K-CBCL) and the Adult Self-Report (K-ASR) were used to evaluate stress levels in children and caregivers, respectively. Results: Questionnaires were provided to 150 caregivers who agreed to participate. However, only 76 copies of the K-CBCL and 75 copies of the K-ASR were collected. The mean K-CBCL and K-ASR $t$ scores were in the normal range. The K-CBCL score correlated positively with the K-ASR score $(p$ value $<0.5)$. K-CBCL externalizing problems score correlated positively with the age at the start of rehabilitation, and the K-CBCL and K-ASR externalizing problems scores correlated negatively with home treatment delivered by caregivers. Conclusions: Stress levels of children and caregivers were closely related. Home rehabilitation provided by caregivers reduced stress in both caregivers and children. Early rehabilitation did not impart additional psychological burden on caregivers or children.
\end{abstract}

Keywords: development disorder; stress level of children and caregivers; home rehabilitation; early rehabilitation

\section{Introduction}

The life expectancy of pediatric patients has improved significantly with advances in pediatric medical care [1,2]. As a result, the number of pediatric inpatients with developmental disabilities who receive rehabilitation has increased [3]. Children in need of rehabilitation have various diagnoses, including cerebral palsy, developmental delay, genetic disorders, and traumatic brain injury. They typically require long-term support from their families, doctor, and physical therapist and have problems in motor development and cognitive, language, and social areas [4]. Therefore, the comprehensive rehabilitation needs of pediatric patients are increasing and the benefits of early intervention have been emphasized [5].

Children receiving rehabilitation can be stressed by many factors. Recently, early rehabilitation has been emphasized, and this could impart a psychological and physical burden $[5,6]$. The socioeconomic status of the caregiver and the frequency of rehabilitation treatment could affect the stress level of the child [7]. 
Previous studies have evaluated the psychological status and quality of life of caregivers of children with disability [8-11]. Rentinck et al. found that parents caring for a child with cerebral palsy had a higher level of stress and worse mental health than parents of children without a disability [12]. Caregivers of children with disabilities face many stressors and demands. Home treatment aims to involve the parents in providing rehabilitation for their child and varies according to the child's needs. Doctors have emphasized the importance of home treatment by caregivers, especially for patients with cerebral palsy, because inpatient rehabilitation treatments are not feasible or affordable. Novak et al. reported that an occupational therapy home program delivered by parents was clinically effective in children with cerebral palsy [13].

Early intervention, performed during the first year of life when the brain is undergoing rapid development, is thought to be more effective than intervention delivered later in development. This is based on the perception that neural networks that remain intact after brain injury could be enhanced through learning-induced plasticity. Animal studies demonstrate an important period of motor plasticity and activity-dependent reorganization of the motor projection pattern before 1 year of age [14]. However, few studies have investigated the effects of early rehabilitation on psychological status in children.

In this study, our first objective was to investigate the stress levels of caregivers and children receiving rehabilitation. Our second objective was to explore the relationship between stress levels and both early treatment and home treatment.

\section{Methods}

\subsection{Study Design and Participants}

This was a prospective study conducted in children with development disorders who underwent rehabilitation at the Division of Pediatric Rehabilitation, Department of Rehabilitation Medicine, Asan Medical Center between June 2016 and September 2016. The children with development disorders were over 1.5 years of age and we obtained informed consent from their caregivers. The Korean version of the Child Behavior Checklist (K-CBCL), the Korean version of the Adult Self-Report (K-ASR), and the questionnaire were provided to caregivers. Age, diagnosis, and comorbid medical problems were obtained from medical records. The study was approved by the institutional review board of the hospital (IRB no. 2016-0049).

\subsection{Measurements}

The K-CBCL was used to evaluate the stress level of the child receiving rehabilitation. The K-CBCL is a Korean standardized form of the Child Behavior Checklist [15]; it is used widely to identify behavioral and emotional problems in children and in both research and clinical practice. It has been used to evaluate the stress levels of children [16-19] and was included in a large multicultural study due to its validation against the K-CBCL [20]. There are several versions of the K-CBCL. In this study, the K-CBCL 1.5-5 was used for children aged from 1.5 years to 5 years and the K-CBCL 6-18 was used for children aged from 6 years to 18 years.

The K-CBCL 1.5-5 consists of a 100-item checklist and the K-CBCL 6-18 consists of a 119-item checklist, both of which are scored on a three-point scale $(0=$ not true; $1=$ somewhat or sometimes true; 2 = very true or often true). The K-CBCL $1.5-5$ is grouped into seven subscales: emotionally reactive, anxious/depressed, withdrawn, somatic complaints, sleep problems, attention problems, and aggressive behavior. The emotionally reactive, anxious/depressed, somatic complaints, and withdrawn subscales are combined to give a score for internalizing problems (IP). The attention problems and aggressive behavior subscales are combined to give a score for externalizing problems (EP). The total problems (TP) score is obtained by combining all seven subscales (IP, EP, sleep problems) and other problems [21]. The K-CBCL 6-18 is grouped into eight subscales: anxious/depressed, withdrawn/depressed, somatic complaints, social problems, thought problems, attention problems, 
rule-breaking behavior, and aggressive behavior. The IP score is composed of three subscales (withdrawn/depressed, anxious/depressed, somatic complaints), the EP score is composed of two subscales (rule-breaking behavior, aggressive behavior), and the TP score is obtained by combining all eight subscales (IP, EP, social problems, thought problems, attention problems) and other problems.

The K-ASR was used to evaluate the stress level of the caregiver [21-23]. The ASR is a reliable and valid self-report tool suitable for individuals aged 18-59 years and was designed to assess the extent of a variety of emotional and behavioral problems in adults. The ASR is a 126-item checklist that uses a three-point scale. The items are grouped into eight subscales: anxious/depressed, withdrawn, somatic complaints, aggressive behavior, rule-breaking behavior, intrusive, thought problems, and attention problems. The IP score is composed of three subscales (anxious/depressed, withdrawn, somatic complaints), the EP score of three subscales (aggressive behavior, rule-breaking behavior, intrusive), and the TP score of all eight subscales (IP, EP, thought problems, and attention problems) [24].

For both the K-CBCL and the K-ASR, a higher raw score indicates more problem behaviors [22,25]. Raw scores were transformed into $t$ scores that indicate whether or not the individual presents deviant behavior or deficiency competencies in relation to norms for their age and gender. The $t$ scores for IP, $\mathrm{EP}$, and TP were standardized based on the percentile scores obtained from theKorean population [26]. A $t$ score $\leq 59$ (84th percentile) was classified as normal, $60-63$ (85-90th percentile) as borderline clinical, and $\geq 64$ (91st percentile) as clinical [27].

The questionnaire was used to evaluate factors that may affect the stress levels of children and their caregivers. It evaluates the characteristics of the rehabilitation (number of sessions of per week, number of institutions involved, and total duration of any treatments delivered at home by the caregiver) and the socioeconomic conditions (education level of the caregiver, caregiver's annual income, marital status, and whether or not they live with their child).

\subsection{Statistical Analysis}

Relationships between variables were evaluated using Spearman's correlation coefficient. Each factor and stress index were assessed by Spearman's correlation coefficient. A $t$-test was used to compare the mean scores of each stress index between children who received some treatment at home by their caregiver (home treatment group) and children who received no treatment at home by their caregiver (no home treatment group). A $p$ value below 0.05 was considered statistically significant.

\section{Results}

\subsection{Participant Characteristics}

The demographic details of the children and caregivers are presented in Table 1. A total of 150 caregivers agreed to participate. The K-CBCL, K-ASR, and questionnaires were distributed personally. For the K-CBCL, K-ASR, and questionnaires, the response rate was 50.6\% (76 completed questionnaires), $50.0 \%$ (75 completed questionnaires), and $48.6 \%$ (73 completed questionnaires), respectively. The low response rate may have been due to the time required to complete all questionnaires (approximately $1 \mathrm{~h}$ ) or reluctance to answer all items within the questionnaires. The 76 completed K-CBCL questionnaires comprised $81 \mathrm{~K}-\mathrm{CBCL} 1.5-5(80.2 \%)$ and $15 \mathrm{~K}-\mathrm{CBCL}$ 6-18 (19.7\%).

All participating children lived with their parents. The mean \pm standard deviation age of the children was $4.4 \pm 3.1$ years (range, $1.5-16$ years). Thirty-three $(43.4 \%)$ children had cerebral palsy, $18(23.7 \%)$ had a genetic disorder, $16(15.8 \%)$ had delayed development of unknown etiology (Table 1$)$. The number of rehabilitation treatments per week was $6.2 \pm 3.6$ (range, 1-14), delivered at $2.8 \pm 1.3$ institutions (range, 1-6). Forty (53\%) children received rehabilitation treatment from their caregiver at home. Twenty-six (34.2\%) children had started rehabilitation before the age of 6 months, $22(28.9 \%)$ 
had started between the ages of 6 and 12 months, 14 (18.4\%) children had started between the ages of 12 and 24 months, and $14(18.4 \%)$ had started after the age of 24 months (Table 1).

The mean age of the caregivers was $36.7 \pm 3.62$. One caregiver was divorced. Most of the caregivers were female $(98.7 \%)$ and college graduates $(71.2 \%)$ and had cared for their child for more than 3 years $(46.6 \%)$.

Table 1. Characteristics of the study subjects.

\begin{tabular}{|c|c|}
\hline Characteristics of Children & \\
\hline Number of children & 76 \\
\hline Age (years) & $4.4 \pm 3.1$ \\
\hline Sex $(F: M)$ & $42: 34$ \\
\hline \multicolumn{2}{|l|}{ Diagnosis } \\
\hline Cerebral palsy & 33 \\
\hline Genetic disorder & 18 \\
\hline Developmental delay, unknown etiology & 16 \\
\hline Intellectual disability & 6 \\
\hline Other disease & 3 \\
\hline Number of rehabilitation sessions per week & $6.2 \pm 3.6$ \\
\hline Number of institutions involved in the rehabilitation & $2.8 \pm 1.3$ \\
\hline Home treatment provided by caregivers & 40 \\
\hline \multicolumn{2}{|l|}{ Age at which rehabilitation was first initiated (n) } \\
\hline$<6$ months & 26 \\
\hline 6-12 months & 22 \\
\hline 12-24 months & 14 \\
\hline$\geq 24$ months & 14 \\
\hline \multicolumn{2}{|l|}{ Characteristics of Caregivers } \\
\hline Number of caregivers & 75 \\
\hline Age (years) & $36.7 \pm 3.62$ \\
\hline $\operatorname{Sex}(\mathrm{F}: M)$ & $74: 1$ \\
\hline \multicolumn{2}{|l|}{ Marital status } \\
\hline Divorced & 1 \\
\hline Married state & 72 \\
\hline \multicolumn{2}{|l|}{ Socioeconomic status } \\
\hline \multicolumn{2}{|l|}{ Education level } \\
\hline High school graduate & 14 \\
\hline College graduate & 52 \\
\hline Graduate school graduate & 7 \\
\hline \multicolumn{2}{|l|}{ Annual income } \\
\hline$<30$ million won & 11 \\
\hline 30-50 million won & 22 \\
\hline 50-70 million won & 20 \\
\hline$\geq 70$ million won & 20 \\
\hline \multicolumn{2}{|l|}{ Period of caregiving } \\
\hline$<2$ years & 19 \\
\hline $2-3$ years & 20 \\
\hline$\geq 3$ years & 34 \\
\hline
\end{tabular}

\subsection{Stress Levels of Children}

The mean K-CBCL TP $t$ score was 54.1. Median IP and EP $t$ score was 52.8 and 52.5, respectively. Among the 76 children, seven (9\%) were in the clinical range for the TP score and $12(16 \%)$ were in the borderline clinical range. Four children (5\%) were in the clinical range for the IP score and $10(13 \%)$ were in the borderline clinical range. Seven children (9\%) were in the clinical range for the EP score and nine $(12 \%)$ were in the borderline clinical range (Table 2$)$. 
Table 2. Prevalence of behavior problems in children and caregivers.

\begin{tabular}{llcccc}
\hline & & Normal & Borderline Clinical & Clinical & Total \\
\hline \multirow{5}{*}{ Children } & Total behavior problems & $57(75)$ & $12(16)$ & $7(9)$ & 76 \\
& Internalizing problems & $62(82)$ & $10(13)$ & $4(5)$ & 76 \\
& Externalizing problems & $60(79)$ & $9(12)$ & $7(9)$ & 76 \\
\hline \multirow{3}{*}{ Caregivers } & Total behavior problems & $66(88)$ & $3(4)$ & $6(8)$ & 75 \\
& Internalizing problems & $61(81)$ & $12(16)$ & $2(3)$ & 75 \\
& Externalizing problems & $68(91)$ & $2(3)$ & $5(6)$ & 75 \\
\hline
\end{tabular}

Values are presented as number (\%).

\subsection{Stress Levels of Caregivers}

The mean K-ASR TP $t$ score was 49.0. Six caregivers (8\%) were in the clinical range for the TP score and three caregivers ( $4 \%$ ) were in the borderline clinical range. Two caregivers $(3 \%)$ were in the clinical range for the IP score and $12(16 \%)$ were in the borderline clinical range. Five caregivers $(6 \%)$ were in the clinical range for the EP score and two (3\%) were in the borderline clinical range (Table 2).

\subsection{Relations between Measured Factors}

The K-CBCL TP score correlated positively with the K-ASR TP, IP, and EP scores, the duration of caregiving, and the age at which rehabilitation was started (Figure 1). Figure 1 displays the relationship between the timing of rehabilitation and child's stress level of TP and EP. The K-CBCL TP score did not correlate with the number of rehabilitation sessions per week, the number of institutions across which rehabilitation was delivered, or socioeconomic status. The K-CBCL EP score correlated positively with the K-ASR TP, IP, and EP scores, the duration of caregiving, and the age at which rehabilitation was started (Figure 1). The K-CBCL IP score correlated positively with the K-ASR TP, IP, and EP scores but not with any other measured variables (Table 3). The K-CBCL EP score and the K-ASR EP score differed across the home treatment and no home treatment groups (Table 4). Table 4 shows that home treatment affects the EP scores of children and caregivers. In addition, children receiving home treatment had a higher number of rehabilitation sessions per week.

Externalizing problems score has a significant difference between the groups, and a $p$ value below 0.05 was considered statistically significant.

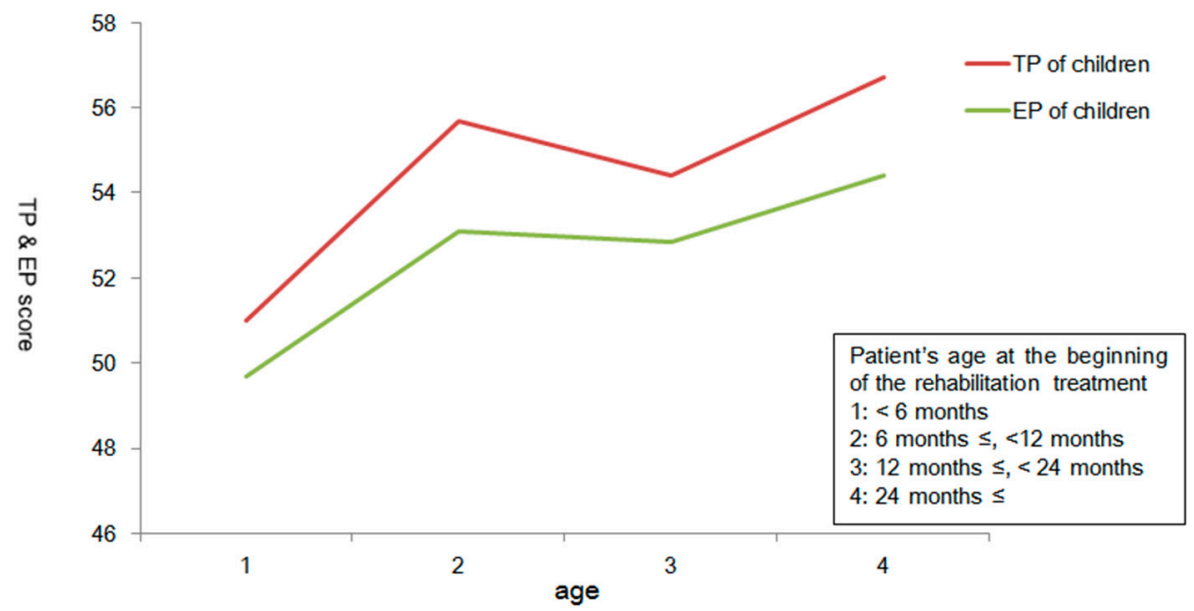

Figure 1. The relationship between the timing of rehabilitation and child's stress level. EP: the externalizing problems are obtained by combining attention problems and aggressive behavior. TP: the total problems score is obtained by combining all eight subscales. 
Table 3. Correlations between all measured factors.

\begin{tabular}{|c|c|c|c|c|c|c|c|c|c|c|c|c|c|}
\hline & & $\begin{array}{l}\text { TP of } \\
\text { Child }\end{array}$ & $\begin{array}{l}\text { IP of } \\
\text { Child }\end{array}$ & $\begin{array}{l}\text { EP of } \\
\text { Child }\end{array}$ & $\begin{array}{c}\text { TP of } \\
\text { Caregiver }\end{array}$ & $\begin{array}{c}\text { IP of } \\
\text { Caregiver }\end{array}$ & $\begin{array}{c}\text { EP of } \\
\text { Caregiver }\end{array}$ & $\begin{array}{l}\text { Number of } \\
\text { Institutions } \\
\text { Involved in } \\
\text { Rehabilitation }\end{array}$ & $\begin{array}{c}\text { Number of } \\
\text { Rehabilitation } \\
\text { Sessions Per } \\
\text { Week } \\
\end{array}$ & $\begin{array}{l}\text { Annual } \\
\text { Income of } \\
\text { Caregiver }\end{array}$ & $\begin{array}{l}\text { Education } \\
\text { Level of } \\
\text { Caregiver }\end{array}$ & $\begin{array}{l}\text { Period of } \\
\text { Caregiving }\end{array}$ & $\begin{array}{c}\text { Age at the } \\
\text { Start of } \\
\text { Starting } \\
\text { Rehabilitation }\end{array}$ \\
\hline \multirow{2}{*}{ TP of child } & Rho & - & 0.786 & 0.877 & 0.360 & 0.389 & 0.322 & 0.221 & 0.208 & 0.125 & -0.052 & 0.291 & 0.289 \\
\hline & $p$ & & $0.000^{*}$ & 0.000 * & $0.002^{*}$ & $0.001 *$ & 0.005 * & 0.060 & 0.078 & 0.293 & 0.660 & $0.013 *$ & $0.011^{*}$ \\
\hline \multirow{2}{*}{ IP of child } & Rho & 0.786 & - & 0.543 & 0.407 & 0.436 & 0.351 & 0.161 & 0.213 & 0.107 & 0.193 & 0.011 & 0.133 \\
\hline & $p$ & $0.000 *$ & 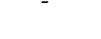 & 0.000 * & $0.000 *$ & $0.000 *$ & $0.002 *$ & 0.175 & 0.070 & 0.366 & 0.101 & 0.929 & 0.251 \\
\hline \multirow{2}{*}{ EP of child } & Rho & 0.877 & 0.543 & - & 0.237 & 0.273 & 0.223 & 0.177 & 0.140 & 0.111 & -0.113 & 0.386 & 0.244 \\
\hline & $p$ & $0.000^{*}$ & $0.000^{*}$ & & $0.041^{*}$ & $0.017^{*}$ & 0.054 & 0.134 & 0.239 & 0.351 & 0.339 & $0.001 *$ & $0.034^{*}$ \\
\hline \multirow{2}{*}{ TP of caregiver } & Rho & 0.360 & 0.407 & 0.237 & - & 0.904 & 0.882 & 0.122 & -0.011 & -0.52 & 0.183 & -0.75 & 0.177 \\
\hline & $p$ & $0.002 *$ & $0.000 *$ & $0.041^{*}$ & & $0.000^{*}$ & 0.200 & 0.309 & 0.924 & 0.666 & 0.125 & 0.531 & 0.129 \\
\hline \multirow{2}{*}{ IP of caregiver } & Rho & 0.389 & 0.436 & 0.273 & 0.904 & - & 0.695 & 0.140 & 0.013 & -0.035 & 0.187 & -0.030 & 0.140 \\
\hline & $p$ & $0.001 *$ & $0.000 *$ & 0.017 * & $0.000 *$ & & $0.000 *$ & 0.239 & 0.917 & 0.773 & 0.116 & 0.802 & 0.233 \\
\hline \multirow{2}{*}{ EP of caregiver } & Rho & 0.322 & 0.351 & 0.223 & 0.882 & 0.695 & - & 0.008 & -0.117 & -0.116 & 0.156 & -0.142 & 0.224 \\
\hline & $p$ & $0.005 *$ & $0.002 *$ & 0.054 & 0.200 & $0.000 *$ & & 0.945 & 0.329 & 0.331 & 0.190 & 0.233 & 0.053 \\
\hline \multirow{2}{*}{$\begin{array}{l}\text { Number of institutions } \\
\text { involved in rehabilitation }\end{array}$} & Rho & 0.221 & 0.161 & 0.177 & 0.122 & 0.140 & 0.008 & - & 0.621 & -0.046 & 0.031 & 0.306 & -0.040 \\
\hline & $p$ & 0.060 & 0.175 & 0.134 & 0.309 & 0.239 & 0.945 & & $0.000 *$ & 0.698 & 0.792 & $0.008^{*}$ & 0.736 \\
\hline \multirow{2}{*}{$\begin{array}{l}\text { Number of rehabilitation } \\
\text { sessions per week }\end{array}$} & Rho & 0.208 & 0.213 & 0.140 & -0.011 & 0.013 & -0.117 & 0.621 & - & -0.065 & -0.059 & 0.145 & -0.124 \\
\hline & $p$ & 0.078 & 0.070 & 0.239 & 0.924 & 0.917 & 0.329 & 0.000 & & 0.586 & 0.617 & 0.220 & 0.297 \\
\hline \multirow{2}{*}{$\begin{array}{l}\text { Annual income } \\
\text { of caregiver }\end{array}$} & Rho & 0.125 & 0.107 & 0.111 & -0.52 & -0.035 & -0.116 & -0.046 & -0.065 & - & 0.312 & 0.082 & 0.135 \\
\hline & $p$ & 0.293 & 0.366 & 0.351 & 0.666 & 0.773 & 0.331 & 0.698 & 0.586 & - & $0.007^{*}$ & 0.488 & 0.254 \\
\hline \multirow{2}{*}{$\begin{array}{l}\text { Education level } \\
\text { of caregiver }\end{array}$} & Rho & -0.052 & 0.193 & -0.113 & 0.183 & 0.187 & 0.156 & 0.031 & -0.059 & 0.312 & - & -0.178 & 0.049 \\
\hline & $p$ & 0.660 & 0.101 & 0.339 & 0.125 & 0.116 & 0.190 & 0.792 & 0.617 & $0.007^{*}$ & & 0.132 & 0.682 \\
\hline \multirow{2}{*}{ Period of caregiving } & Rho & 0.291 & 0.011 & 0.386 & -0.75 & -0.030 & -0.142 & 0.306 & 0.145 & 0.082 & -0.178 & - & -0.069 \\
\hline & $p$ & $0.013^{*}$ & 0.929 & 0.001 * & 0.531 & 0.802 & 0.233 & $0.008^{*}$ & 0.220 & 0.488 & 0.132 & & 0.561 \\
\hline \multirow{2}{*}{$\begin{array}{l}\text { Age at the start } \\
\text { of rehabilitation }\end{array}$} & Rho & 0.289 & 0.133 & 0.244 & 0.177 & 0.140 & 0.224 & -0.040 & -0.124 & 0.135 & 0.049 & -0.069 & - \\
\hline & $p$ & $0.011^{*}$ & 0.251 & $0.034^{*}$ & 0.129 & 0.233 & 0.053 & 0.736 & 0.297 & 0.254 & 0.682 & 0.561 & \\
\hline
\end{tabular}

${ }^{*} p$ value $<0.05$ by spearman correlation analysis. IP: the internalizing problems are obtained by combining emotionally reactive, anxious/depressed, somatic complaints, and withdrawn subscales. EP: the externalizing problems are obtained by combining attention problems and aggressive behavior. TP: the total problems score is obtained by combining all eight subscales (internalizing problems (IP), externalizing problems (EP), social problems, thought problems, attention problems) and other problems. 
Table 4. Stress levels in the home treatment group and the no home treatment group.

\begin{tabular}{llccc}
\hline & & $\begin{array}{c}\text { Children } \\
\text { Receiving Home } \\
\text { Treatment (n=43) }\end{array}$ & $\begin{array}{c}\text { Children Not } \\
\text { Receiving Home } \\
\text { Treatment (n= 33) }\end{array}$ & $p$ \\
\hline \multirow{3}{*}{ Children } & Total problems score & $53.07 \pm 8.47$ & $55.36 \pm 8.15$ & 0.24 \\
& Internalizing problems score & $53.28 \pm 6.92$ & $54.24 \pm 6.99$ & 0.52 \\
& Externalizing problems score & $50.47 \pm 6.63$ & $54.94 \pm 8.31$ & $0.03{ }^{*}$ \\
\hline \multirow{2}{*}{ Caregivers } & Total problems score & $47.70 \pm 11.05$ & $50.84 \pm 8.31$ & 0.18 \\
& Internalizing problems score & $49.35 \pm 9.58$ & $52.94 \pm 10.70$ & 0.13 \\
& Externalizing problems score & $45.98 \pm 10.93$ & $51.25 \pm 7.68$ & $0.02 *$ \\
\hline & Number of rehabilitation & $6.95 \pm 3.88$ & $4.97 \pm 2.91$ & $0.02 *$ \\
& sessions per week & & & \\
\hline
\end{tabular}

Values are expressed as the mean ( \pm standard deviation) $t$-score. ${ }^{*} p$ values $<0.05$ compare the two groups.

\section{Discussion}

We evaluated stress levels in caregivers and children who received rehabilitation and evaluated factors that could affect stress levels. We found that the stress levels of children receiving rehabilitation correlated positively with the stress level of the caregiver. The stress levels of the children and their caregivers were lower if the child was receiving some rehabilitation treatment at home than if they were receiving no treatment at home but did not correlate with number of rehabilitation sessions per week or socioeconomic status.

Some of the children in this study reported remarkably high levels of stress. The proportion of children in the clinical range was $9 \%, 5 \%$, and $9 \%$ for TP, IP, and EP, respectively, which is similar to the $10 \%$ expected in the general population [28]. In a previous study, the mean CBCL $t$ score of non-fostered children was 51.7 [29], which is slightly lower than the mean $t$ score in our study (54.1). However, when compared with the general population, our study group could be regarded as normal.

There have been previous studies of psychological problems in caregivers but fewer studies on the affected children [10,30-33]. There are some studies of the psychological problems of children with various diseases [34-37], particularly cerebral palsy [35,38-41]. Pain intensity, pain anxiety, parental stress and support, executive function, gross motor function, poorer intellect, and having disabled siblings are associated with psychological problems [35]. Parkes et al. evaluated psychological problems in children aged 8-12 years with cerebral palsy using the total difficulties score, which represents behavioral and emotional symptoms [35]. Of the parents who reported that their children had psychological problems, $95 \%$ said they also had family burden over a year.

Although studies have evaluated the psychological status of children receiving rehabilitation (but not their caregivers), few have done so simultaneously. Spiel at al. investigated parental stress and behavioral problems in children with cerebral palsy [38]. Moo's life stressors and social resources inventory was used to evaluate caregiver stress and behavioral problems were identified using the CBCL. The CBCL IP score of children with cerebral palsy was associated with the situational stress of their caregivers, a measure which included health, economic situation, and life events [38]. The CBCL EP score of children with cerebral palsy was significantly associated with the situational stress and relational stress of their caregivers; the latter included social relationships with partners, family, friends, neighbors, and teachers [38].

In the present study, we found that home rehabilitation treatment was significantly associated with the EP score of children and their caregivers. This indicates that home rehabilitation treatment delivered by the caregiver may reduce stress in both the caregiver and the child. Based on the concept that parents are the principal component of the rehabilitation treatment team, our hospital has encouraged and educated all caregivers about home rehabilitation treatment. The therapist directly trained parents about the rehabilitation treatment appropriate for their children. Forty out of the 76 educated caregivers who completed questionnaires conducted home rehabilitation. Twenty-six of 
these performed home rehabilitation for 30 min every day, and 14 provided more than 30 min per day. The importance of home rehabilitation has been emphasized in various fields [42-46] and has been studied in children with cerebral palsy [13]. Novak et al. demonstrated that children with cerebral palsy who received occupational therapy at home had better occupational performance after 8 weeks than those who did not receive occupational therapy at home [13]. The psychological status of children was evaluated using the Children's Assessment of Participation and Enjoyment, and there was no significant difference in psychological status between children who did and did not receive therapy at home. Claudio et al. found that caregiver-directed home-based intensive bimanual training in children with unilateral spastic cerebral palsy improved dexterity and performance of a functional goal [47]. However, this study did not investigate psychological status.

Early rehabilitation is helpful for the development of children, but it is not clear how it affects psychology. It may be a stress burden for caregivers and children to start rehabilitation too early. The benefit of early rehabilitation interventions for preterm infants has been emphasized recently [48]. The expected outcome of a developmental care intervention is improvement in overall physical, social, cognitive, and emotional development. However, we have not be able to find out how early rehabilitation treatment could affect psychological status in children with development disorder. In the current study, we identified the age of the child at the onset of rehabilitation to determine whether early rehabilitation treatment was related to stress in children with development disorders. Children who started rehabilitation early in their life had low TP and EP scores. In other words, early rehabilitation did not impart a psychological burden on children or their caregivers.

This study has several strengths. Firstly, we determined the effect of home rehabilitation delivered by caregivers on indices of stress. Home rehabilitation provided by the caregivers was associated with lower stress levels for both the caregiver and the child. Secondly, we demonstrated that early rehabilitation intervention did not increase the stress levels of children or their caregiver. Thirdly, we evaluated the stress levels of children receiving rehabilitation and their caregivers simultaneously and demonstrated that the two were correlated. Finally, a previous study evaluated the psychological burden of children with cerebral palsy, but our subjects included a variety of diseases.

The study has some limitations. Firstly, the sample size was small. The length of time required to fill out the questionnaire and the inclusion of sensitive issues likely contributed to the low response rate. Secondly, there was no control group, i.e., a group that received no rehabilitation, with which to compare the stress of children with development disorders. However, as children with development disorders were all receiving rehabilitation, it was not possible or ethical to include this control group. Moreover, the one of the principal limitations is the heterogeneity of the subjects. Children's disease and age might affect their stress, so this study might have some bias in this regard. Therefore, well designed future research with homogeneity of pathology and age are needed. Moreover, disease severity was not studied; it is necessary to reflect upon how the severity of the disease affects stress in children and their caregivers.

In conclusion, this study demonstrated that the stress levels of children with developmental disorders were closely related to the stress levels of their caregivers. Early rehabilitation intervention did not impart an additional psychological burden to the caregiver or the child. Home rehabilitation provided by the caregiver was associated with lower stress levels of EP for of both the caregiver and the child.

Author Contributions: Conceptualization, I.Y.S. and E.J.K.; methodology, I.Y.S. and S.H.K.; formal analysis, S.H.K.; investigation, S.H.K.; resources, S.H.K.; data curation, J.P. and N.H.; writing-original draft preparation, S.H.K.; writing—review and editing, I.Y.S. and S.H.K.; supervision, I.Y.S. and E.J.K. All authors have read and agreed to the published version of the manuscript.

Funding: No external funding was received to prepare this manuscript.

Acknowledgments: The authors would like to thank the families for their participation in this study and the therapist who helped to collect the questionnaires.

Conflicts of Interest: The authors declare no conflict of interest. 


\section{References}

1. Khairy, P.; Ionescu-Ittu, R.; Mackie, A.S.; Abrahamowicz, M.; Pilote, L.; Marelli, A.J. Changing mortality in congenital heart disease. J. Am. Coll. Cardiol. 2010, 56, 1149-1157. [CrossRef] [PubMed]

2. Cooke, R.W. Preterm mortality and morbidity over 25 years. Arch. Dis. Child. Fetal Neonatal Ed. 2006, 91, F293-F294. [CrossRef] [PubMed]

3. Vohr, B.R.; Msall, M.E. Neuropsychological and functional outcomes of very low birth weight infants. Semin. Perinatol. 1997, 21, 202-220. [CrossRef]

4. Anderson, V.; Catroppa, C. Advances in postacute rehabilitation after childhood-acquired brain injury: A focus on cognitive, behavioral, and social domains. Am. J. Phys. Med. Rehabil. 2006, 85, 767-778. [CrossRef] [PubMed]

5. Ni, W.-S.; Zhang, Y.-H.; Li, T.; Zhao, D.-Y.; Tan, J.-T.; Zhu, T.-W.; Xie, L.-J. Early rehabilitation intervention reduces the incidence of extrauterine growth retardation in preterm infants. Zhongguo Dang dai er ke za zhi= Chin. J. Contemp. Pediatrics 2018, 20, 97-101.

6. Hopkins, R.O.; Choong, K.; Zebuhr, C.A.; Kudchadkar, S.R. Physical Therapy and Rehabilitation in Pediatric Critical Care: Transforming PICU Culture to Facilitate Early Rehabilitation. J. Pediatric Intensive Care 2015, $4,204$.

7. Biegel, D.E.; Milligan, S.E.; Putnam, P.L.; Song, L.-Y. Predictors of burden among lower socioeconomic status caregivers of persons with chronic mental illness. Community Ment. Health J. 1994, 30, 473-494. [CrossRef]

8. Raina, P.; O’Donnell, M.; Rosenbaum, P.; Brehaut, J.; Walter, S.D.; Russell, D.; Swinton, M.; Zhu, B.; Wood, E. The health and well-being of caregivers of children with cerebral palsy. Pediatrics 2005, 115, e626-e636. [CrossRef]

9. Basaran, A.; Karadavut, K.I.; Uneri, S.O.; Balbaloglu, O.; Atasoy, N. The effect of having a children with cerebral palsy on quality of life, burn-out, depression and anxiety scores: A comparative study. Eur. J. Phys. Rehabil. Med. 2013, 49, 815-822.

10. Guillamon, N.; Nieto, R.; Pousada, M.; Redolar, D.; Munoz, E.; Hernandez, E.; Boixados, M.; Gomez-Zuniga, B. Quality of life and mental health among parents of children with cerebral palsy: The influence of self-efficacy and coping strategies. J. Clin. Nurs. 2013, 22, 1579-1590. [CrossRef]

11. Davis, K.; Gavidia-Payne, S. The impact of child, family, and professional support characteristics on the quality of life in families of young children with disabilities. J. Intellect. Dev. Disabil. 2009, 34, 153-162. [CrossRef] [PubMed]

12. Rentinck, I.C.; Ketelaar, M.; Jongmans, M.J.; Gorter, J.W. Parents of children with cerebral palsy: A review of factors related to the process of adaptation. Child Care Health Dev. 2007, 33, 161-169. [CrossRef] [PubMed]

13. Novak, I.; Cusick, A.; Lannin, N. Occupational therapy home programs for cerebral palsy: Double-blind, randomized, controlled trial. Pediatrics 2009, 124, e606-e614. [CrossRef]

14. Friel, K.M.; Chakrabarty, S.; Martin, J.H. Pathophysiological mechanisms of impaired limb use and repair strategies for motor systems after unilateral injury of the developing brain. Dev. Med. Child Neurol. 2013, 55 (Suppl. 4), 27-31. [CrossRef]

15. Oh, K.J.; Lee, H.; Hong, K.E.; Ha, E.H. Korean Child Behavior Checklist; Chung Ang Aptitude: Seoul, Korea, 1997.

16. Graham-Bermann, S.A.; Levendosky, A.A. Traumatic stress symptoms in children of battered women. J. Interpers. Violence 2016, 13, 111-128. [CrossRef]

17. Banez, G.A.; Compas, B.E. Children's and parents' daily stressful events and psychological symptoms. J. Abnorm Child Psychol. 1990, 18, 591-605. [CrossRef]

18. Nakajima-Yamaguchi, R.; Morita, N.; Nakao, T.; Shimizu, T.; Ogai, Y.; Takahashi, H.; Saito, T.; Nakatani, Y.; Fukushima, T. Parental post-traumatic stress symptoms as predictors of psychosocial problems in children treated for cancer. Int. J. Environ. Res. Public Health 2016, 13, 812. [CrossRef]

19. Bae, S.M.; Kang, J.M.; Chang, H.Y.; Han, W.; Lee, S.H. PTSD correlates with somatization in sexually abused children: Type of abuse moderates the effect of PTSD on somatization. PLoS ONE 2018, 13, e0199138. [CrossRef]

20. Ivanova, M.Y.; Dobrean, A.; Dopfner, M.; Erol, N.; Fombonne, E.; Fonseca, A.C.; Frigerio, A.; Grietens, H.; Hannesdottir, H.; Kanbayashi, Y.; et al. Testing the 8-syndrome structure of the child behavior checklist in 30 societies. J. Clin. Child Adolesc. Psychol. 2007, 36, 405-417. [CrossRef] [PubMed] 
21. Achenbach, T.M.; Rescorla, L.A. Manual for the ASEBA Preschool Forms E Profiles: An Integrated System of Multi-Informant Assessment; Child Behavior Checklist for Ages 1 1/2-5; Language Development Survey; Caregiver-Teacher Report Form; University of Vermont, Research Center for Children, Youth \& Families: Burlington, VT, USA, 2000.

22. Achenbach, T.M.; Rescorla, L.A. Manual for the ASEBA Adult Forms and Profiles; University of Vermont, Research Center for Children, Youth, and Families: Burlington, VT, USA, 2003.

23. Achenbach, T.M.; Rescorla, L. Manual for the ASEBA School-Age Forms E Profiles; ASEBA: Burlington, VT, USA, 2001.

24. Ivanova, M.Y.; Achenbach, T.M.; Rescorla, L.A.; Tumer, L.V.; Ahmeti-Pronaj, A.; Au, A.; Maese, C.A.; Bellina, M.; Caldas, J.C.; Chen, Y.C.; et al. Syndromes of self-reported psychopathology for ages 18-59 in 29 societies. J. Psychopathol. Behav. Assess. 2015, 37, 171-183. [CrossRef]

25. Achenbach, T.M.; Bernstein, A.; Dumenci, L. DSM-oriented scales and statistically based syndromes for ages 18 to 59: Linking taxonomic paradigms to facilitate multitaxonomic approaches. J. Pers. Assess. 2005, 84, 49-63. [CrossRef]

26. Oh, K.J.; Ha, E. K-CBCL Child Behavior Checklist; Huno Consulting: Seoul, Korea, 2007.

27. Bordin, I.A.; Rocha, M.M.; Paula, C.S.; Teixeira, M.C.; Achenbach, T.M.; Rescorla, L.A.; Silvares, E.F. Child Behavior Checklist (CBCL), Youth Self-Report (YSR) and Teacher's Report Form (TRF): An overview of the development of the original and Brazilian versions. Cad. Saude Publica 2013, 29, 13-28. [CrossRef] [PubMed]

28. Achenbach, T.M.; Edelbrock, C.S. Manual for the Child Behavior Checklist: And Revised Child Behavior Profile; University of Vermont, Department of Psychiatry: Burlington, VT, USA, 1983.

29. Hulsey, T.C.; White, R. Family characteristics and measures of behavior in foster and nonfoster children. Am. J. Orthopsychiatry 1989, 59, 502-509. [CrossRef]

30. Bella, G.P.; Garcia, M.C.; Spadari-Bratfisch, R.C. Salivary cortisol, stress, and health in primary caregivers (mothers) of children with cerebral palsy. Psychoneuroendocrinology 2011, 36, 834-842. [CrossRef]

31. Estes, A.; Olson, E.; Sullivan, K.; Greenson, J.; Winter, J.; Dawson, G.; Munson, J. Parenting-related stress and psychological distress in mothers of toddlers with autism spectrum disorders. Brain Dev. 2013, 35, 133-138. [CrossRef] [PubMed]

32. Lv, R.; Wu, L.; Jin, L.; Lu, Q.; Wang, M.; Qu, Y.; Liu, H. Depression, anxiety and quality of life in parents of children with epilepsy. Acta Neurol. Scand. 2009, 120, 335-341. [CrossRef] [PubMed]

33. Manuel, J.; Naughton, M.J.; Balkrishnan, R.; Paterson Smith, B.; Koman, L.A. Stress and adaptation in mothers of children with cerebral palsy. J. Pediatr. Psychol. 2003, 28, 197-201. [CrossRef]

34. Warschausky, S.; Kewman, D.; Kay, J. Empirically supported psychological and behavioral therapies in pediatric rehabilitation of TBI. J. Head Trauma Rehabil. 1999, 14, 373-383. [CrossRef]

35. Parkes, J.; White-Koning, M.; Dickinson, H.O.; Thyen, U.; Arnaud, C.; Beckung, E.; Fauconnier, J.; Marcelli, M.; McManus, V.; Michelsen, S.I.; et al. Psychological problems in children with cerebral palsy: A cross-sectional European study. J. Child Psychol. Psychiatry 2008, 49, 405-413. [CrossRef]

36. Emerson, E. Prevalence of psychiatric disorders in children and adolescents with and without intellectual disability. J. Intellect. Disabil. Res. 2003, 47, 51-58. [CrossRef]

37. Herring, S.; Gray, K.; Taffe, J.; Tonge, B.; Sweeney, D.; Einfeld, S. Behaviour and emotional problems in toddlers with pervasive developmental disorders and developmental delay: Associations with parental mental health and family functioning. J. Intellect. Disabil. Res. 2006, 50, 874-882. [CrossRef] [PubMed]

38. Sipal, R.F.; Schuengel, C.; Voorman, J.M.; Van Eck, M.; Becher, J.G. Course of behaviour problems of children with cerebral palsy: The role of parental stress and support. Child Care Health Dev. 2010, 36, 74-84. [CrossRef] [PubMed]

39. Yamaguchi, R.; Nicholson Perry, K.; Hines, M. Pain, pain anxiety and emotional and behavioural problems in children with cerebral palsy. Disabil. Rehabil. 2014, 36, 125-130. [CrossRef] [PubMed]

40. Whittingham, K.; Bodimeade, H.L.; Lloyd, O.; Boyd, R.N. Everyday psychological functioning in children with unilateral cerebral palsy: Does executive functioning play a role? Dev. Med. Child Neurol. 2014, 56, 572-579. [CrossRef] [PubMed]

41. Levy-Zaks, A.; Pollak, Y.; Ben-Pazi, H. Cerebral palsy risk factors and their impact on psychopathology. Neurol. Res. 2014, 36, 92-94. [CrossRef] 
42. Wuytack, F.; Devane, D.; Stovold, E.; McDonnell, M.; Casey, M.; McDonnell, T.J.; Gillespie, P.; Raymakers, A.; Lacasse, Y.; McCarthy, B. Comparison of outpatient and home-based exercise training programmes for COPD: A systematic review and meta-analysis. Respirology 2018, 23, 272-283. [CrossRef] [PubMed]

43. Zheng, H.; Davies, R.J.; Black, N.D. Web-based monitoring system for home-based rehabilitation with stroke patients. In Proceedings of the 18th IEEE Symposium on Computer-Based Medical Systems (CBMS'05), Dublin, Ireland, 23-24 June 2005; pp. 419-424.

44. Warrington, D.; Cholowski, K.; Peters, D. Effectiveness of home-based cardiac rehabilitation for special needs patients. J. Adv. Nurs. 2003, 41, 121-129. [CrossRef]

45. Geddes, J.M.; Chamberlain, M.A. Home-based rehabilitation for people with stroke: A comparative study of six community services providing co-ordinated, multidisciplinary treatment. Clin. Rehabil. 2001, 15, 589-599. [CrossRef]

46. Taylor, R.S.; Watt, A.; Dalal, H.M.; Evans, P.H.; Campbell, J.L.; Read, K.L.; Mourant, A.J.; Wingham, J.; Thompson, D.R.; Pereira Gray, D.J. Home-based cardiac rehabilitation versus hospital-based rehabilitation: A cost effectiveness analysis. Int. J. Cardiol. 2007, 119, 196-201. [CrossRef]

47. Ferre, C.L.; Brandao, M.; Surana, B.; Dew, A.P.; Moreau, N.G.; Gordon, A.M. Caregiver-directed home-based intensive bimanual training in young children with unilateral spastic cerebral palsy: A randomized trial. Dev. Med. Child Neurol. 2017, 59, 497-504. [CrossRef]

48. Garcia, A.; O’Reilly, A.; Matone, M.; Kim, M.; Long, J.; Rubin, D.M. The influence of caregiver depression on children in non-relative foster care versus kinship care placements. Matern. Child Health J. 2015, 19, 459-467. [CrossRef] [PubMed]

(C) 2020 by the authors. Licensee MDPI, Basel, Switzerland. This article is an open access article distributed under the terms and conditions of the Creative Commons Attribution (CC BY) license (http://creativecommons.org/licenses/by/4.0/). 